\title{
Predicting Shear Strength of RC Columns Using Artificial Neural Networks
}

\author{
Said A ${ }^{1,}$, Gordon $\mathrm{N}^{2}$ \\ 1 Architectural Engineering Department, The Pennsylvania State university, 104 Engineering Unit A, \\ University Park, PA. \\ 2 Structural Engineering Division, Tesla Motors Inc., Las Vegas, Nevada. \\ * Corresponding Author: aly.said@engr.psu.edu
}

Received: 01-01-2018

Accepted: 08-06-2019

\begin{abstract}
A primary objective in the seismic design of structures is to ensure that the capacity of individual members of a structure exceeds the associated demands. For reinforced concrete (RC) columns, several parameters involving steel and concrete material properties control behavior and strength. Furthermore, it is unrealistic to simply consider the shear strength calculation as the sum of concrete and steel contributions while accounting for axial force when, in fact, all those parameters are interacting. Consequently, it is challenging to reasonably estimate the shear capacity of a column while accounting for all the factors. This study investigates the viability of using artificial neural networks (ANN) to estimate the shear capacity of RC columns. Results from ANN are compared with both experimental values and calculated values, using semi-empirical and empirical formulas from the literature. Results show that ANNs are significantly accurate in predicting shear strength when trained with accurate experimental results, and meet or exceed the performance of existing empirical formulas. Accordingly, ANNs could be used in the future for analytical predictions of shear strength of RC members.
\end{abstract}

Key words: reinforced concrete, neural network, artificial intelligence, shear, seismic, columns.

\section{Introduction}

In the seismic design of structures, it is essential to ensure that the deformation capacities of a structure and its components exceed the associated deformation demands. This concept is implicitly addressed in capacity-based design procedures, and is an explicit core requirement of displacement-based design procedures. Thus, it is desirable that structures are designed with high ductility and large deformation capacities according to seismic provisions. Shear failure of reinforced concrete (RC) members is inherently brittle, resulting in a significant drop in lateral load resistance at low deformation; this is highly undesirable in seismic design. Several studies have demonstrated that the shear strength of RC members degrades substantially under cyclic loading when compared to the flexural strength of the member (Ascheim et al., 1992; Priestley et al., 1994; Moehle et al., 2002; Biskinis et al., 2004). Accordingly, existing seismic design guidelines for RC structures require special reinforcement for zones where plastic hinges are expected to form in order to ensure that brittle modes of failure are avoided.

Nonetheless, in many cases, due to the complex interaction between the parameters that affect shear strength of a member, empirical equations formulated based on analytical reasoning are often proposed in order to predict the shear strength of these members. These empirical models have been continuously and significantly improved, as shown by Biskinis et al. (2004). Recent procedures issued by the U.S. Federal Emergency Management Agency (FEMA) for seismic evaluation of existing structures (FEMA-356, 2000) and for the seismic design of new structures (FEMA-368, 2000) involve member verifications explicitly in terms of member deformations. These procedures provide a strong motivation to develop an accurate, dependable quantification of load and deformation capacities of RC members. Quantification of load and deformation 
capacities of RC members is a difficult task due to their non-linear and complex behavior under seismic loading. Accordingly, existing equations in the literature need to be reexamined and verified using a large amount of experimental data, the more recent information available in the literature, and modern analytical techniques.

\section{Objectives}

This study aims to improve upon existing empirical equations and models by implementing artificial intelligence algorithms to predict the shear strength of RC columns based on a number of different variables. Artificial neural networks (ANN) have been developed and trained to predict the shear resistance for rectangular and circular RC columns under axial load and cyclic lateral loading. A database has been compiled that consists of column specimens that have been loaded cyclically and failed in shear or in shear after flexural yielding (flexure shear).

\section{Experimental Database}

The experimental database used was obtained from the Pacific Earthquake Engineering Research Structural Performance Database (PEER-SPD). PEER-SPD was chosen because the hysteresis of load-displacement data was readily available for nearly all column specimens in the database. This was necessary to form the load-displacement envelopes in order to determine column displacement and lateral loads at yield and ultimate failure as well as to determine the experimental values for the shear resistance, $V r$. By applying a uniform approach for evaluating shear strength of RC columns, the authors believe that the database that was used will have a more consistent dataset. The experimental values of the shear resistance, $V r$, were obtained by analyzing the force-displacement data for the column, determining the maximum loading, and using a value of $75 \%$ of the maximum load. This $75 \%$ is an average determined by systematically analyzing the force-displacement loops; following the approach of Elwood (2002), a yield point was defined as the corner point of a bilinear envelope of the first loading cycle on the loaddeflection diagram. The value of the force at this point was defined as $V r$ by Elwood (2002); however, for consistency and simple identification, an average of all specimens was taken at this point to be $75 \%$ of the peak resistance. Software was written to automatically determine these points from the hysteresis; the source code is available upon request.

\section{Artificial Neural Networks}

Artificial neural networks (ANN) are powerful computational tools inspired by the understanding and abstraction of the structure of biological neurons and the internal operation of the human brain (Haykin, 1994). The most important concept of ANNs is the way in which data is processed. Each ANN is composed of highly interconnected nodes or neurons used to process information. This structure allows ANNs to closely model the way that the human brain forms connections to solve problems and learn by example, or trial-and-error. A neural network must be "trained" for their specific application. This training process is accomplished by providing a network with a large amount of data to build connections between neurons. This is analogous to the same process that occurs in biological systems during the learning process. Synaptic connections between neurons are built and reconfigured over numerous generations of training. Increasingly, neural networks are applied to real-world applications where problems are too complex to solve by means of conventional methods or for problems where an algorithmic solution would be too complex or undefined. They also can be used where algorithmic solutions have been developed, but do not yield high accuracy in the results. Many applications of ANNs have shown superior accuracy to empirical algorithms in these cases.

Several types of neural networks exist, the most common of which is the continuous multi-layer perceptron (CMP). This type of network is based on recursive generational evaluation, consisting of various layers of neurons passing information between each other. The first layer, called the 'input layer', has the same number of neurons equal to the number of variables. Each 
successive layer is called a 'hidden layer', and may contain more or less neurons than the preceding layer. A final layer, called the 'output layer', contains the same number of neurons as the number of outputs expected by the response. In the case of no hidden layers, a neural network can only act on linear tasks. All problems that are capable of a solution with a CMP can be solved with only one hidden layer; however, more layers can be used, and may result in more accurate responses. A sample of a neural network architecture is shown in Figure 1.

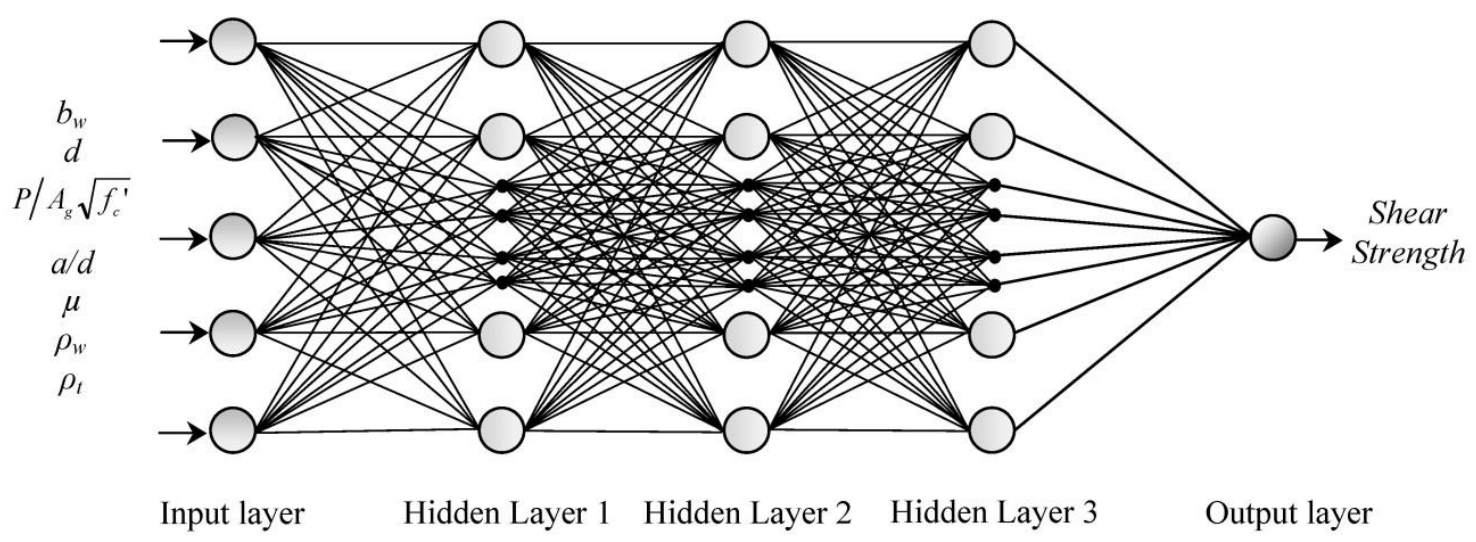

Fig 1. An example of the structure of an artificial neural network (ANN).

Each neuron in a hidden layer first creates a linear combination of the outputs of the previous layer and a bias to introduce variation. These combinations and biases are called the weights. The neurons in the hidden layer then create a non-linear function based on the inputs. The most commonly used function is called the logistic function. This function varies from 0 to 1 , and maps to a real value that may be positive or negative as well as large or small. As a requirement of using this function, all input data must first be normalized into a range from 0 to 1 . One of the methods of normalizing the data input is by using the following equation:

$$
x_{t}=\frac{\left(x-x_{\min }\right)}{\left(x_{\max }-x_{\min }\right)}
$$

where $x_{t}$ is the scaled value of variable $x$, and $x_{\min }$ and $x_{\max }$ are the minimum and maximum values for the dataset, respectively. This normalizes any input data to a percentage value of the range of the data used.

The training is based on making the mean squared error (MSE) in the network as small as possible. This is done over many training cycles, because when the network is initially presented with a large seemingly random distribution, the MSE will be very large. The training process modifies the 'weights' of each neuron in an attempt to decrease the MSE of the net to a global minimum over each cycle. Once the training process is complete, another set of testing data is presented to the network, and the results are compared with experimental results.

In order to evaluate the performance of the ANN model, the absolute average error $(A A E)$ of the ratio of the calculated shear capacity, $V r_{\text {calculated }}$, to the experimentally measured shear capacity, $V r_{\text {experimental, }}$ was used to measure how accurately the network predicts the shear capacity relative to the experimental data. The $A A E$ was calculated using the following equation:

$$
A A E=\frac{1}{n} \sum \frac{\left|V r_{\text {experimentd }}-V r_{\text {calculated }}\right|}{V r_{\text {experimentd }}} \times 100
$$

Furthermore, to determine the coefficient of variation among the ratio of $V r_{\text {experimental }} / V r_{\text {calculated, }}$ the following equation was used: 


$$
C O V=\frac{\sigma\left(V r_{\text {experimentd }} / V r_{\text {calculated }}\right)}{\mu\left(V r_{\text {experimentd }} / V r_{\text {calculated }}\right)}
$$

where $\mu$ and $\sigma$ are the mean and standard deviation, respectively.

\section{Existing Shear Strength Models}

Three previous models were evaluated for their accuracy in predicting the shear strength of cyclically loaded members. The models evaluated were the ACI 318-14 (2014) shear strength model and the models developed by Priestley et al. (1994), and Moehle et al. (2002).

The ACI 318-11 (2011) model presents the same shear strength prediction model as has been provided by code standards in preceding versions. Along with many of the other equations, this model recognizes a contribution to the shear strength by the steel $\left(V_{S}\right)$ as well as a contribution by the concrete $\left(V_{C}\right)$, as described in Equations 11-2 (units: psi, in).

$$
V_{n}=V_{C}+V_{S}
$$

Equations 11-5 and 11-6 (herein Eqs. 5 and 6, respectively) provided a detailed approach to account for the moment and shear interaction and their effect on the concrete contribution as follows:

$$
\begin{gathered}
V_{c}=1.9 \lambda \sqrt{f^{\prime}{ }_{c}}+2500 \rho_{w} \frac{V_{u} d}{M_{m}} b_{w} d<3.5 \lambda \sqrt{f^{\prime}{ }_{c}} b_{w} d \sqrt{1+\frac{P}{500 A_{g}}} \\
M_{m}=M_{u}-P \frac{4 h-d}{8} \\
V_{S}=\frac{A_{v} f_{y t} d}{s}
\end{gathered}
$$

In the case that $M_{m}$ is negative, it is permitted to use the upper bound of $V_{c}$ as the concrete contribution. For spirally reinforced columns, $V_{s}$ is multiplied by $(\sin \alpha+\cos \alpha)$, where $\alpha$ is the angle between inclined stirrups and longitudinal axis of the member. Nonetheless, the most recent ACI-318-14 (2014), eliminated accounting for $M_{m}$ as an optional additional step, while keeping $M_{u}$ instead. It also kept Equation 22.5.6.1 (formerly 11-4), which accounts for the effect of axial load as follows:

$$
V_{c}=2\left(1+\frac{N_{u} d}{2000 A_{g}}\right) \lambda \sqrt{f^{\prime}{ }_{c}} b_{w} d
$$

Priestley et al. (1994) presented a model that takes into account the displacement ductility, defined by the ratio of the ultimate displacement at failure to the displacement at yield. This ratio is used to define a modification factor that reduces the predicted shear strength of the column. Priestley et al. (1994) divided the strength calculation into three parts: a concrete contribution, $V_{c}$; a steel contribution, $V_{s}$; and an axial load contribution, $V_{p}$. These equations are presented as follows:

$$
V_{R}=V_{C}+V_{P}+V_{S}
$$




$$
\begin{gathered}
V_{C}=k \sqrt{f^{\prime}}{ }_{c} A_{e} \\
V_{P}=\frac{h-c}{2 a} P \\
V_{S}=\frac{A_{v} f_{y t} D^{\prime}}{s} \cot 30^{\circ}
\end{gathered}
$$

where $k$ depends on the member displacement ductility level and the system of units chosen (megapascals or pounds per square inch) as well as on whether the column is expected to be subjected to uniaxial or biaxial ductility demand. In Equation (10), the effective shear area is taken as $A_{e}=0.8 A_{g}$ for both circular and rectangular columns. Figure 2, provided by Priestley et $a l$. (1994), is used to determine $k$ values. In Equation (12), $D^{\prime}$ is taken as the distance between the very outer peripheral loops or spirals of transverse reinforcement, center to center, or $(d-$ $d)^{\prime}$ by some notation. For circular columns, $V_{s}$ is multiplied by $\frac{\pi}{2}$, and $h$ is taken as the overall diameter.

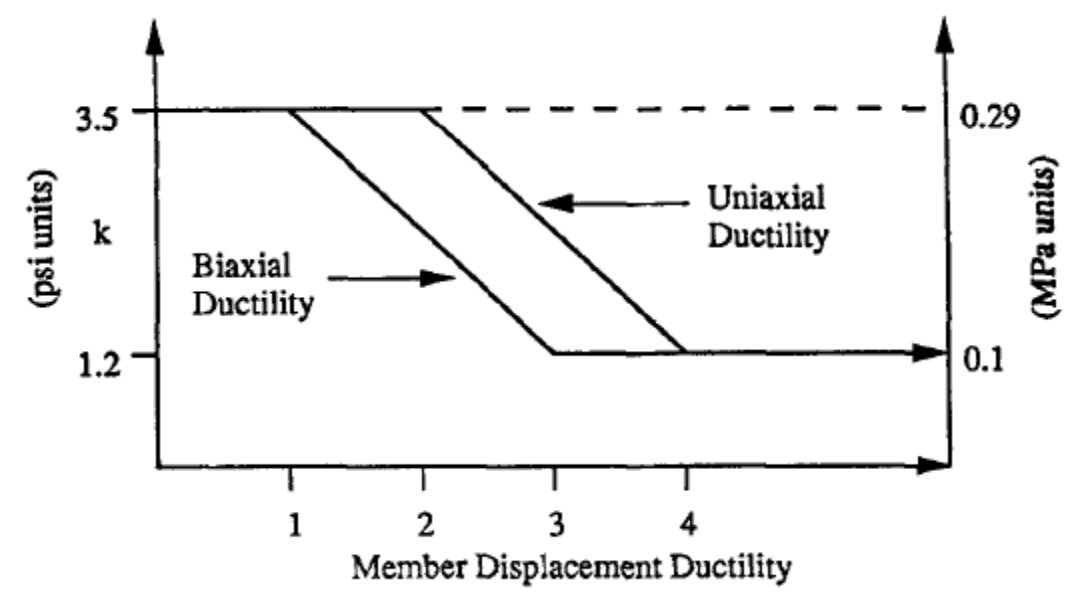

Fig 2. Degradation of concrete shear strength with ductility (Priestley, et al., 1994).

The third model, evaluated for its capacity to predict shear strength, is a model recently proposed by Moehle et al. (2002). This model also recognizes a degradation of shear strength as a result of cyclic loading. However, in contrast to the presentation by Priestley et al. (1994), this model applies the shear degradation factor to both the concrete and steel contributions to shear strength. Doing so results in a more accurate model, as is evidenced by the data. Moehle's equations recognize steel and concrete contributions as separate as well, with the axial load contribution taken into account in the concrete contribution term.

$$
\begin{gathered}
V_{R}=k\left(V_{C}+V_{S}\right) \\
k=0.7 \leq 1.15-0.075 \mu \leq 1.0 \\
V_{c}=0.5 \sqrt{f^{\prime}{ }_{c}}\left(\sqrt{1+\frac{P}{0.5 \sqrt{f^{\prime}}{ }_{c} A_{g}}}\right)\left(A_{g} \frac{d}{a}\right)
\end{gathered}
$$




$$
V_{S}=\frac{\pi}{2} \frac{A_{v} f_{y t} D^{\prime}}{s} \cot 45^{\circ}
$$

In circular columns, $D^{\prime}$ in Equation 16 is taken as (diameter $-2 \times$ cover).

The above models were tested on a database of 120 columns consisting of 65 spirally reinforced circular or octagonal cross-sections and 55 rectangular sections. Octagonal cross-section columns were approximated as circular sections, since the small difference in the concrete area is negligible.

Evaluation of the existing shear strength models for RC columns is shown in Figures 3 through 5 as well as Table 1. Despite the fact that ACI 318-11 does not account for shear degradation under cyclic loading, results are split fairly evenly between over-prediction of shear strength and a conservative prediction, as shown in Figure. However, there are several cases where shear strength has been greatly over-predicted, for example, in the case of Priestley et al. (1994), where the equations greatly over-predict the shear strength of almost all specimens, as shown in Figure 4. This may be attributed to the lack of application of the shear degradation factor to the steel contribution or to the over-estimation of the concrete contribution to shear resistance. Moehle's return to the classical Ritter-Mörsch truss analogy of a 45-degree angle seems to be the most conservative, especially with the shear degradation factor applied to the steel contribution, as illustrated in Figure 5.

Table 1. Statistical Performance of Existing Shear Strength Equations.

\begin{tabular}{|c|c|c|c|c|c|c|c|c|}
\hline \multirow[b]{3}{*}{ Method } & \multicolumn{4}{|c|}{ Rectangular Columns } & \multicolumn{4}{|c|}{ Circular Columns } \\
\hline & \multirow[b]{2}{*}{ AAE (\%) } & \multicolumn{3}{|c|}{$V r_{\text {experimental }} / V r_{\text {Calculated }}$} & \multirow[b]{2}{*}{$\operatorname{AAE}(\%)$} & \multicolumn{3}{|c|}{$V r_{\text {experimental }} / V r_{\text {Calculated }}$} \\
\hline & & Average & SD & $\operatorname{CoV}(\%)$ & & Average & SD & $\mathrm{CoV}(\%)$ \\
\hline Moehle et al. (2001) & $46.6 \%$ & 1.76 & 0.92 & $52.4 \%$ & $42.1 \%$ & 2.12 & 3.33 & $157.5 \%$ \\
\hline Priestley et al. (1994) & $99.3 \%$ & 0.63 & 0.27 & $42.8 \%$ & $82.4 \%$ & 0.71 & 0.40 & $56.9 \%$ \\
\hline $\begin{array}{l}\text { ACI-318-14 eq. } \\
{[22.5 .6 .1]}\end{array}$ & $46.5 \%$ & 0.85 & 0.35 & $40.5 \%$ & $28.2 \%$ & 1.14 & 0.35 & $30.5 \%$ \\
\hline
\end{tabular}

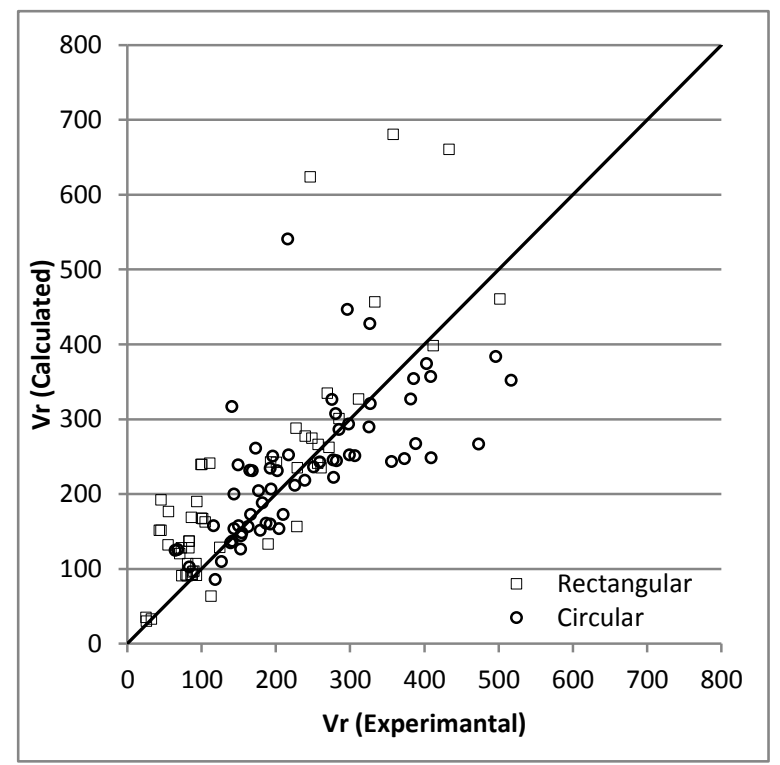

Fig 3. Experimental vs. calculated column shear strength, according to ACI 318-14 (2014) Equation 22.5.6.1. 


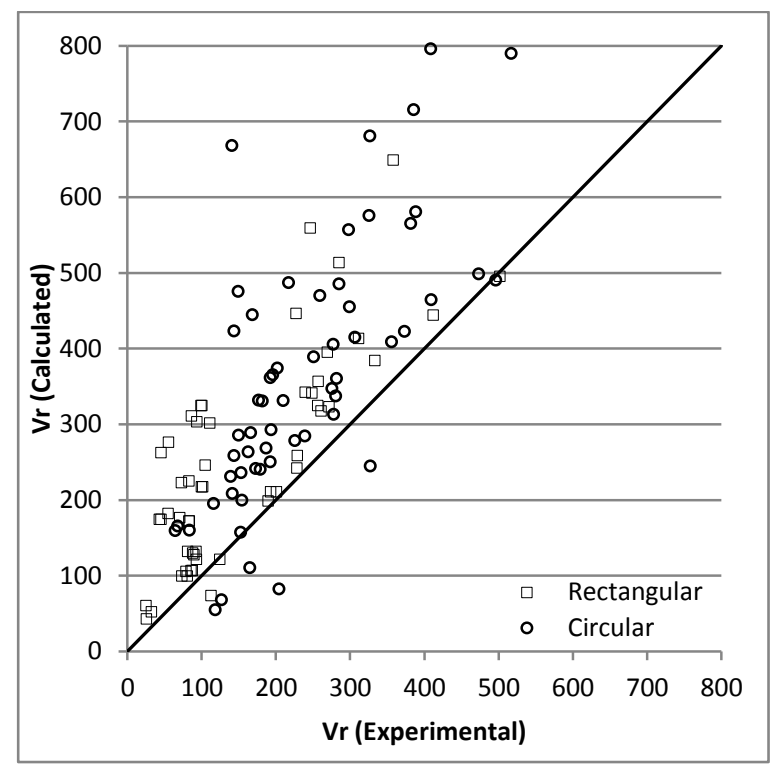

Fig 4. Experimental vs. calculated column shear strength according to the Priestley et al. (1994) model.

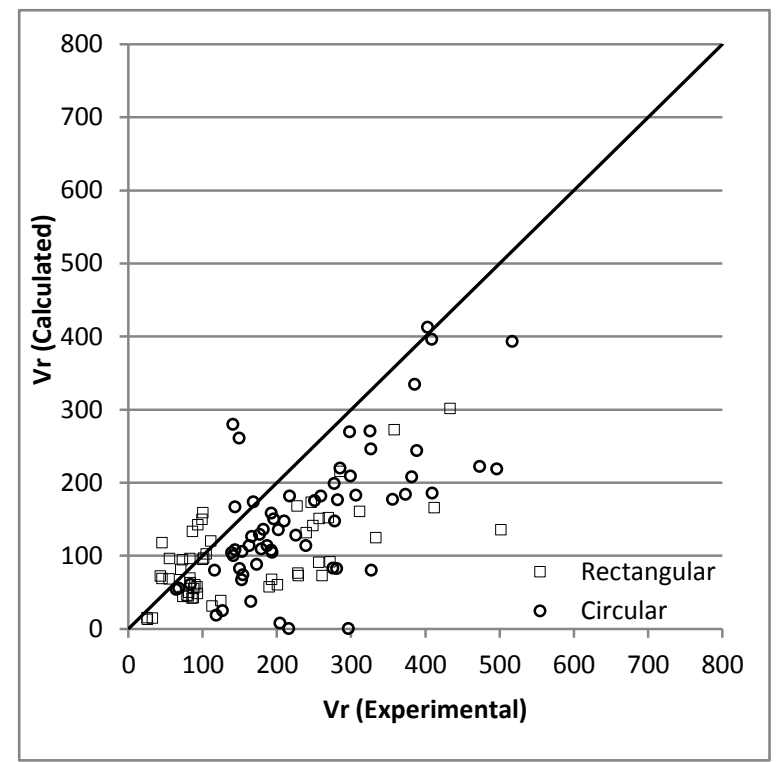

Fig 5. Experimental vs. calculated column shear strength according to the Moehle et al. (2002) model.

The statistical performance of the three approaches presented in this paper, shown in Table 1, indicates that the ACI approach is quite acceptable, taking into account that it is a design standard that needs to conform to a wide range of applications.

\section{ANN Model}

Hundreds of neural network architectures were created and tested, and the top performing networks for circular and rectangular columns were selected. Selection criteria were based on the best fit to the data as well as the lowest absolute mean error. The networks were trained with a subset of the original data. This subset, chosen at random by a Gaussian distribution function, consisted of half the specimens available in the database. The other half was reserved to test the performance of the network. Figures 6(a) and 6(b) illustrate the networks for rectangular and circular columns, respectively. 
For rectangular columns, seven input variables were provided to predict the shear strength of the member. These variables are shown in Table 2. Table 3 illustrates relevant statistical data for each of the top ANN models for rectangular columns. Network NN-321 had the best correlation to the results, and an error mean that leaned more towards the conservative side of prediction, which is preferable.
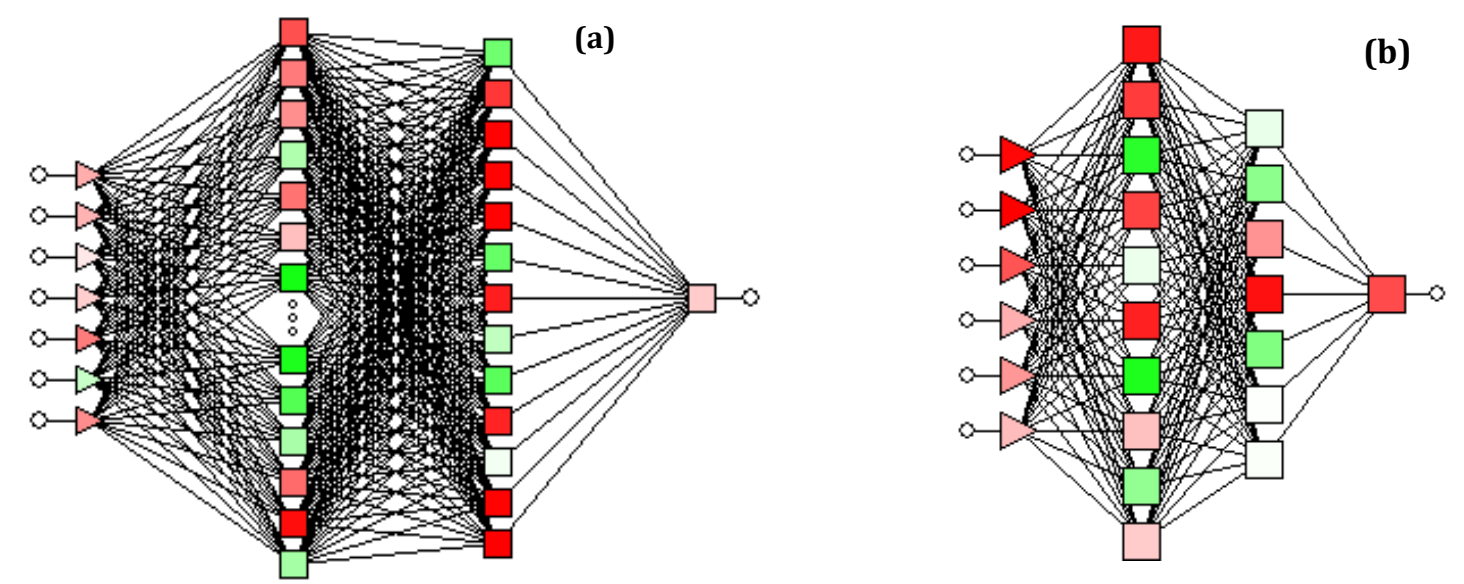

Fig 6. ANN model architecture for (a) NN-321 (rectangular columns) and (b) NN-149 (circular columns).

For circular columns, the same input variables were used to train the networks, with the exception of $b_{w}$ and $d$, and the addition of the column diameter, $D$, bringing the total number of input variables for circular columns to six. Table 3 illustrates the pertinent properties and information about the structure and statistical data of the top ANN model for circular columns. The ANN models used for predicting the shear strength of circular columns were not as robust and efficient, and did not achieve the same confidence in the results as did the rectangular ANNs. However, the confidence was still significantly greater than the previously presented empirical equations.

Table2. ANN Input Variables for Rectangular Columns.

\begin{tabular}{lccl}
\hline Input Variable & Notation & Units & Comments \\
\hline \hline Column Base & $b_{w}$ & length & \\
Effective Depth & $d$ & Length & $\begin{array}{l}\text { Distance from extreme compression fiber to } \\
\text { centroid of longitudinal tension reinforcement }\end{array}$ \\
Axial Load Contribution & $\frac{P}{A_{g} \sqrt{f^{\prime}}}$ & unitless & \\
Aspect Ratio & $\frac{a}{d}$ & unitless & \\
Displacement Ductility & $\mu$ & unitless & $\begin{array}{l}\text { Ratio of ultimate displacement at failure to } \\
\text { displacement at yield }\end{array}$ \\
$\begin{array}{l}\text { Longitudinal Reinforcement } \\
\text { Ratio }\end{array}$ & $\rho_{w}$ & unitless & $\begin{array}{l}\text { Area of longitudinal reinforcement divided by gross } \\
\text { concrete area }\end{array}$ \\
$\begin{array}{l}\text { Volumetric Transverse } \\
\text { Reinforcement Ratio }\end{array}$ & $\rho_{t}$ & unitless & \\
\hline
\end{tabular}


ANN model NN-149 performed the best out of a large number of evaluated ANN models. However, NN-149 had trouble predicting shear strength for columns identified as high outliers. This is typical for many of the properties, especially in ANN modeling, where confidence in the results becomes dependent on the number of test specimens from the database used for training within that range. For that reason, it is recommended that the models are only used within the range of parameters that they are used in training.

Table 3. ANN Properties and Performance Data for Rectangular and Circular Columns.

\begin{tabular}{lcc}
\hline Network & $\begin{array}{c}\text { NN-321 } \\
\text { (Rectangular Columns) }\end{array}$ & $\begin{array}{c}\text { NN-149 } \\
\text { (Circular Columns) }\end{array}$ \\
\hline \hline Data Mean & 158.74 & 253.68 \\
Data S.D. & 113.26 & 130.08 \\
Error Mean & 2.325 & 2.133 \\
Error S.D. & 14.703 & 29.609 \\
Abs E. Mean & 9.635 & 21.719 \\
S.D. Ratio & 0.129 & 0.974 \\
Correlation & 0.992 & 2 \\
\# of Hidden Layers & 2 & 10 \\
\# Hidden Units, Layer 1 & 15 & 7 \\
\# Hidden Units, Layer 2 & 13 & --- \\
\hline
\end{tabular}

\section{Results and Discussion}

In the prediction of shear strength for RC columns under cyclic loading, neural networks prove to be a very valuable tool due to the extremely non-linear nature of the parameters involved contributing to shear strength and the complexity of their interaction. Neural networks extend beyond the typical realm of empirically based equations, but have the important requirement of computing power and a meaningful database to predict the shear strength of columns.

Neural networks can be retrained when new data become available, and actually 'learn' how to predict the shear strength based on all available information, just as humans can. Such capacity makes ANNs very beneficial in the seismic design of structures.

\subsection{Rectangular Columns}

For rectangular columns, the best performing ANN model was capable of predicting the shear strength of concrete columns significantly better than existing models in the literature. Results displayed in Figure 7 shows data points mostly around the $45^{\circ}$ line; this is in clear contrast to the results shown in Figures 3 through 5.

Results listed in Table 3 show the capacity of the network to estimate the shear strength of columns accurately for the wide range of parameters studied. Figure 8 shows the ratio of experimental to calculated column shear strength plotted against the range of several parameters. While most data points are close to the unity line, point clustering is quite common.

Accordingly, it is recommended that new tests target new values of parameters, thus improving the performance of ANN models as well as other models in the literature. 


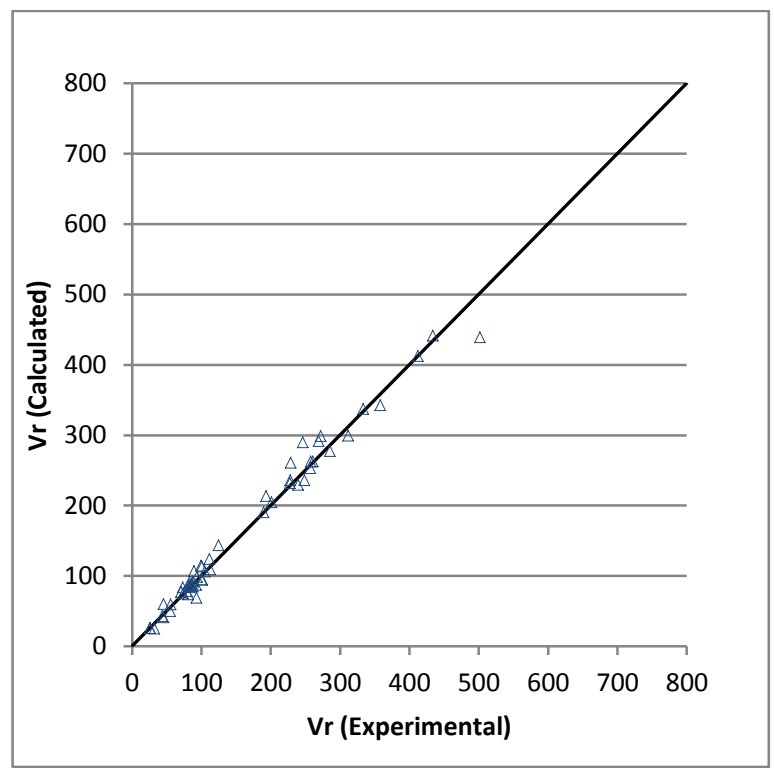

Fig 7. Experimental vs. calculated column shear strength according to the proposed ANN model for rectangular columns.
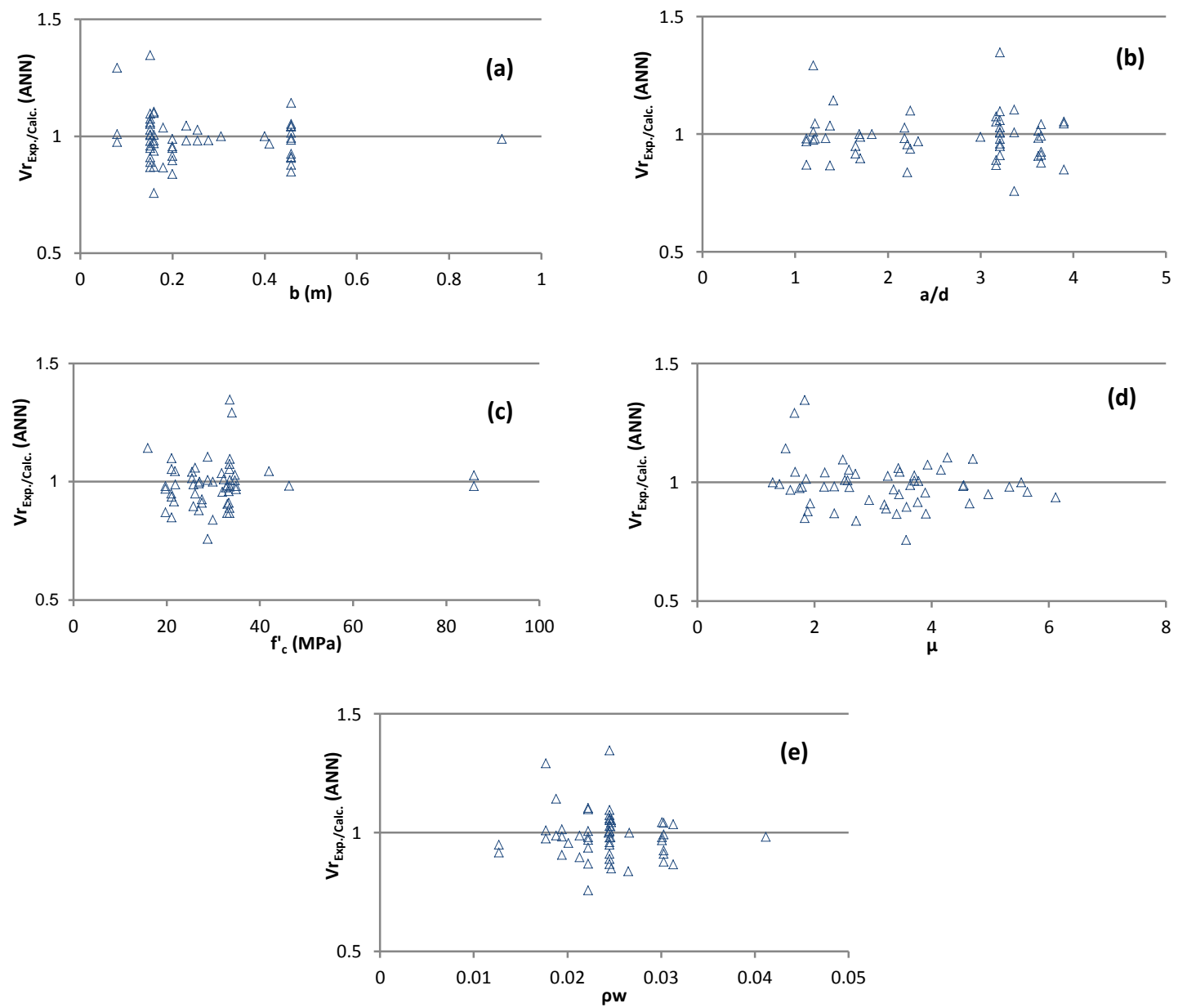

Fig 8. Ratio of experimental-to-calculated column shear strength for the NN-321 model (rectangular columns), plotted against the range of various parameters. 


\subsection{Circular Columns}

For circular columns, the ANN model performance was hindered by the limited number of data points provided. Nonetheless, the ANN model was able to outperform other formulas in the literature, as seen in Figure 9. Furthermore, Figure 10 shows clustering of data for several parameters indicating that some parameters are repeatedly used at the same value, similar to rectangular columns. Figure 10(c) illustrates the need for high strength concrete column testing, since most tested column are below $40 \mathrm{MPa}$. It is also noteworthy that the majority of the estimated results were an underestimation.

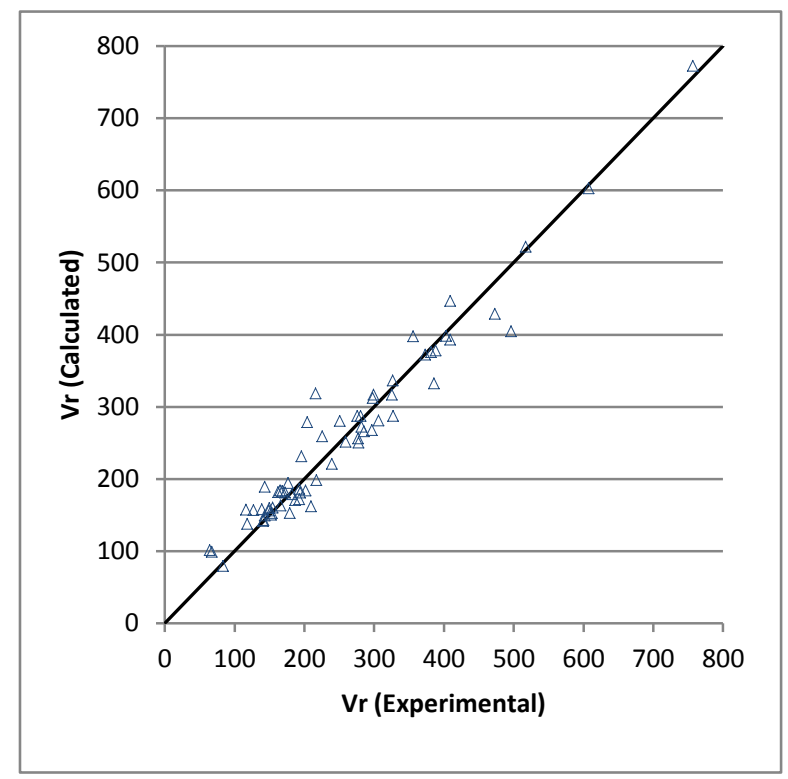

Fig 9. Experimental vs. calculated column shear strength according to the proposed ANN model for circular columns.
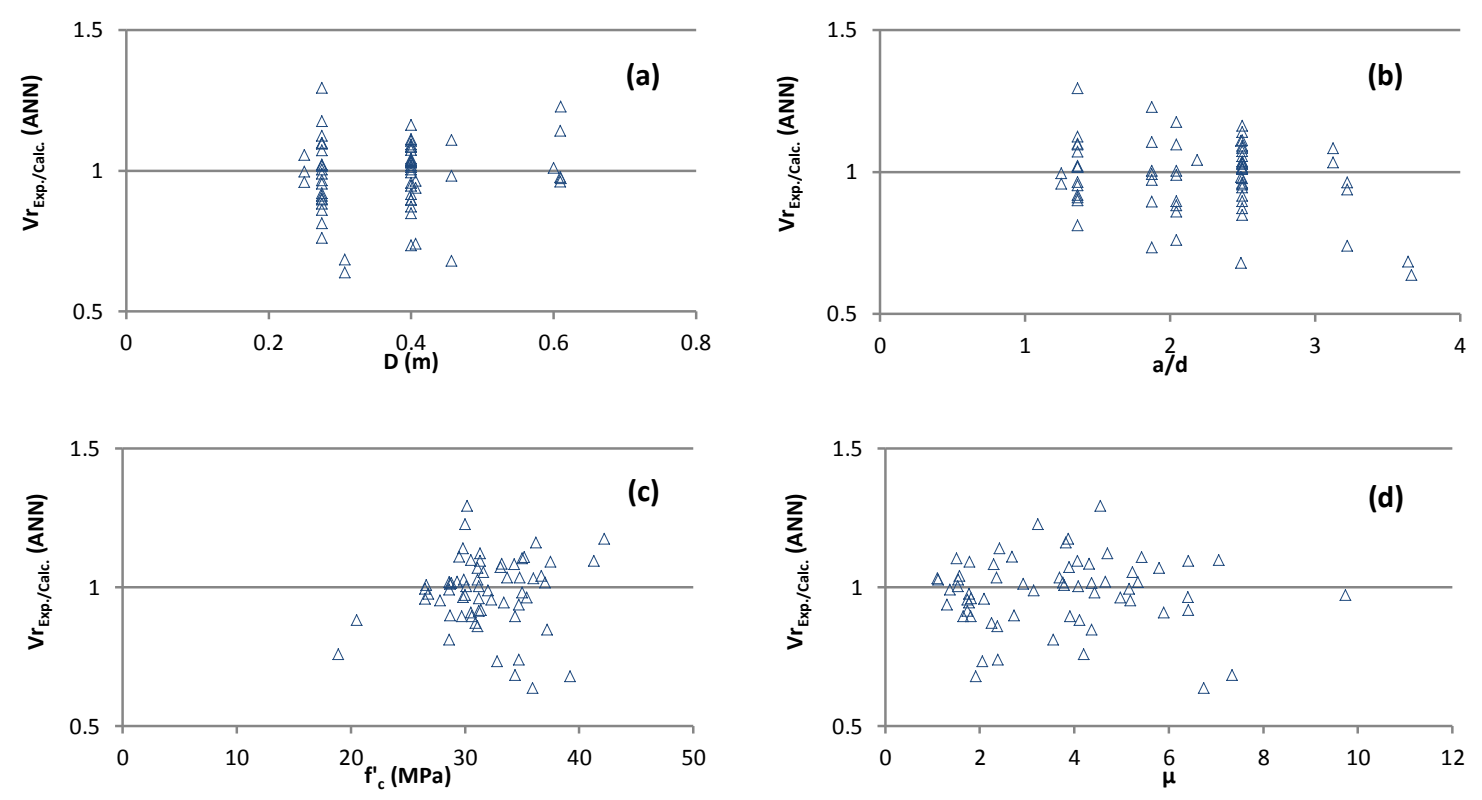


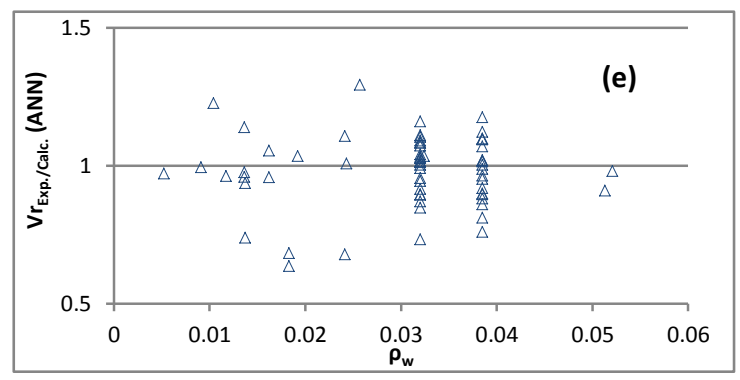

Fig 10. Ratio of experimental-to-calculated column shear strength for the NN-149 model (circular columns) plotted against the range of various parameters.

\section{Conclusion}

In the prediction of shear strength for RC columns under cyclic loading, neural networks proved that it can be a very valuable tool due to the extremely non-linear nature of the parameters involved contributing to shear strength of RC columns. Neural networks extend beyond the typical realm of empirically based equations, but have the necessary computing power to predict the shear strength of the column. Neural networks can be retrained when new data become available, and can actually 'learn' how to predict the shear strength based on previous information, just as humans can. This makes ANNs very beneficial in the seismic design of structures.

For the prediction of the shear strength of rectangular RC columns, the ANN model NN-321 proved to be the best candidate with the best fit to the data, while ANN model NN-149 was the best model for circular columns. Both models outperformed the existing models in the literature examined in this study.

Nonetheless, neural networks have inherent limitation to their capability to predict shear strength of RC columns. ANN models are most accurate within the range of parameters used to train the network and accordingly, they should be cautiously outside the ranges of parameters.

\section{References}

ACI Committee 318 (2011). Building Code Requirements for Structural Concrete (ACI 318-11) and Commentary (ACI 318R-11). Farmington Hills, Mich.: American Concrete Institute.

ACI Committee 318 (2014). Building code requirements for structural concrete (ACI 318-14) and commentary. Farmington Hills, Mich.: American Concrete Institute.

Ascheim, M. A. and J. P. Moehle (1992). Shear Strength and Deformability of RC Bridge Columns Subjected to Inelastic Cyclic Displacements. Report UCB/EERC-92/04. Berkeley, CA: University of California, Earthquake Engineering Research Center.

Biskinis, Dionysis E., George K. Roupakias and Michael N. Fardis (2004). "Degradation of Shear Strength of Reinforced Concrete Members with Inelastic Cyclic Displacements." ACI Structural Journal V. 101.6: 773-783.

Elwood, K. (2002). "Shake Table Tests and Analytical Studies on the gravity Load Collapse of Reinforced Concrete Frames". Ph. D. Dissertation, Department of Civil and Environmental Engineering, University of California Berkeley. p. 419.

Federal Emergency Management Agency, FEMA-356 (2000). "Prestandard and Commentary for Seismic Rehabilitation of Buildings." Washington D.C.

Federal Emergency Management Agency, FEMA-368 (2000),. “NEHRP Recommended Provisions for New Buildings and Other Structures." Washington D.C.

Haykin, S. (1994). Neural Networks. A Comprehensive Foundation. Macmillan, New York, NY. 
Moehle, J. P., K. J. Elwood, and H. Sezen (2002). "Gravity Load Collapse of Building Frames During Earthquakes." ACI SP-197. Behavior and Design of Concrete Structures for Seismic Performance: 215-238.

Priestley, M. J. N., R. Verma and Y Xiao (1994). "Seismic Shear Strength of Reinforced Concrete Columns." Journal of the Structural Division, ASCE V. 120.8. 